OPEN ACCESS

Edited by:

Gillberto Igrejas,

Universidade de Trás-os-Montes e

Alto Douro, Portugal

Reviewed by:

Ana P. Tedim,

Neiker Tecnalia, Spain

Atte Von Wright,

University of Eastern Finland, Finland

*Correspondence:

Mónica Sparo

monicasparo@gmail.com

tThese authors have contributed equally to this work

Specialty section:

This article was submitted to Antimicrobials, Resistance

and Chemotherapy,

a section of the journal

Frontiers in Microbiology

Received: 28 June 2018 Accepted: 28 November 2018

Published: 18 December 2018

Citation:

Sparo M, Delpech G and García Allende N (2018) Impact on

Public Health of the Spread

of High-Level Resistance to Gentamicin and Vancomycin in Enterococci.

Front. Microbiol. 9:3073. doi: 10.3389/fmicb.2018.03073

\section{Impact on Public Health of the Spread of High-Level Resistance to Gentamicin and Vancomycin in Enterococci}

\author{
Mónica Sparo ${ }^{1 *+}$, Gaston Delpech ${ }^{1 \dagger}$ and Natalia García Allende ${ }^{2}$ \\ ' Clinical Department, Medicine School, National University of Central Buenos Aires, Tandil, Argentina, ${ }^{2}$ Hospital Alemán, \\ Buenos Aires, Argentina
}

Antibiotic resistance has turned into a global public health issue. Enterococci are intrinsically resistant to many antimicrobials groups. These bacteria colonize dairy and meat products and integrate the autochthonous microbiota of mammal's gastrointestinal tract. Over the last decades, detection of vanA genotype in Enterococcus faecium from animals and from food of animal origin has been reported. Vancomycin-resistant E. faecium has become a prevalent nosocomial pathogen. Hospitalized patients are frequently treated with broad-spectrum antimicrobials and this leads to an increase in the presence of VanA or VanB vancomycin-resistant enterococci in patients' gastrointestinal tract and the risk of invasive infections. In humans, E. faecium is the main reservoir of VanA and VanB phenotypes. Acquisition of high-level aminoglycoside resistance is a significant therapeutic problem for patients with severe infections because it negates the synergistic effect between aminoglycosides and a cell-wallactive agent. The aac $\left(6^{\prime}\right)$-le-aph ( $\left.2^{\prime \prime}\right)$-la gene is widely spread in $E$. faecalis and has been detected in strains of human origin and in the food of animal origin. Enzyme AAC(6')le-APH $\left(2^{\prime \prime}\right)$-la confers resistance to available aminoglycosides, except to streptomycin. Due to the fast dissemination of this genetic determinant, the impact of its horizontal transferability among enterococcal species from different origin has been considered. The extensive use of antibiotics in food-producing animals contributes to an increase in drug-resistant animal bacteria that can be transmitted to humans. Innovation is needed for the development of new antibacterial drugs and for the design of combination therapies with conventional antibiotics. Nowadays, semi-purified bacteriocins and probiotics are becoming an attractive alternative to the antibiotic in animal production. Therefore, a better understanding of a complex and relevant issue for Public Health such as high-level vancomycin and gentamicin resistance in enterococci and their impact is needed. Hence, it is necessary to consider the spread of vanA E. faecium and high-level gentamicin resistant $E$. faecalis strains of different origin in the environment, and also highlight the potential horizontal transferability of these resistance determinants to other bacteria.

Keywords: enterococci, clinical, foodborne, high-level resistance, gentamicin, vancomycin, clonal, transfer 


\section{INTRODUCTION}

Enterococci are resistant to diverse physicochemical conditions and are widespread in nature. They are capable of growing and surviving under harsh environmental conditions and have been found in soil, plants, birds, and insects (Butler, 2006; Ghosh and Zurek, 2015).

In the intestinal tract of humans and other animals, the genus Enterococcus can be found among their flora. The microbiological and ecological factors that contribute with intestinal colonization are unknown, even though up to $10^{8} \mathrm{CFU} / \mathrm{g}$ of enterococci have been found in human feces. In addition, strains from this genus have been isolated from fermented and dairy products. Moreover, some enterococcal strains have been regarded as food biopreservants and probiotics, although their safety remains questioned (Beibei et al., 2015).

Traditionally, enterococci have not been considered as community-acquired pathogens. Usually, these bacteria do not cause infectious diseases in healthy people, except for occasional urinary tract infections; however, Enterococcus faecium as well as E. faecalis, are prevalent producers of health-care associated opportunistic infections (Woodford and Livermore, 2009). The genomic plasticity of enterococci has contributed with their adaptation to the hospital environment. Their relevance as nosocomial-infections' agents is bolstered by their natural resistance to multiple antimicrobials and an outstanding ability for acquiring and transferring genetic resistance determinants (Werner et al., 2013).

Enterococci express natural (intrinsic) resistance to antibiotics, e.g., clindamycin and trimethoprimsulfamethoxazole. In addition, enterococci show a naturally low-level resistance to gentamicin. Minimum inhibitory concentration (MIC) values to gentamicin range from 6 to $48 \mu \mathrm{g} / \mathrm{mL}$ (Chow, 2000).

Antimicrobials consumption constitutes an important risk factor for colonization with multi-drug resistant enterococci because of the suppression of the competitive indigenous microbiota in the gastrointestinal tract. The increased number of gut enterococci, due to the decrease of competitive gut indigenous flora, frequently precedes bloodstream infections (Ubeda et al., 2010; Reyes et al., 2017).

Antimicrobials can be used in animal husbandry with therapeutic, prophylactic/metaphylactic and growth promotion purposes. Despite the use of antibiotics as growth promoters has been forbidden in many countries, worldwide, foods supplemented with antimicrobials are freely acquired in several countries with no veterinarian control, including in Argentina. This leads to bacterial exposure to subtherapeutic concentrations of antibiotics and, hence, it may promote the expression of antibiotic resistance (Andersson and Hughes, 2014). Antimicrobials employed for human therapies and also used in animal production (in decreasing order) are tetracyclines, penicillins, macrolides, sulfonamides, aminoglycosides, lincosamides, and cephalosporins (Love et al., 2011; Kuehn, 2014). Specifically, ceftiofur, sulfamides and tetracyclines are used for prevention and treatment of pneumonia in pigs; gentamicin and neomycin are employed for the therapy of bacterial diarrhea (Dewey et al., 1999; EFSA, 2011).

The addition of antibiotics for growth promotion in animal feed became a common practice without rigorous testing. The mechanism of action in growth promotion induced by antibiotics appears to be related to the reduction of pathogenic bacteria in the intestines. The concentration of antimicrobials used for growth promotion has often been lower than that used for therapy and prophylaxis. These sub-therapeutic doses of antibiotics often create an auspicious condition for selecting antibiotic resistant bacteria (Van Immerseel et al., 2004; Dibner and Richards, 2005). Previously, McDonald et al. (2001) reported antimicrobial resistant enterococci in food produced with animals fed with antibiotics in sub-therapeutic doses.

Extensive use of antimicrobials in animal husbandry has exerted a considerable pressure for the genesis of antimicrobialresistant bacteria in the environment, such as vancomycinresistant enterococci (López et al., 2009; Ruzauskas et al., 2009; Marshall and Levy, 2011; Nieto-Arribas et al., 2011; Ribeiro et al., 2011; Sánchez Valenzuela et al., 2013).

Furthermore, enterococci, due to their characteristics of gastrointestinal colonization, environmental persistence, natural and acquired resistance to different antimicrobials and their availability to transfer genes horizontally, can be used as biomarkers of antimicrobial resistance in intensive husbandry.

\section{TRANSFERABLE GENETIC DETERMINANTS OF ANTIMICROBIAL RESISTANCE}

Intensive breeding of animals, especially poultry, pigs and cattle, facilitates the selection, spread and resistance determinants transfer of resistant bacteria. Increased antimicrobials resistance in colonizing bacteria from animals and food of this origin was documented (Normanno et al., 2007).

The extended and permanent use of antimicrobials for therapy purposes and growth promotion purposes in husbandry contributed with drug-resistant bacteria selection in humans. When antimicrobials are used in low doses and in prolonged cycles, a selective pressure is exerted that favors the propagation of drug-resistant bacteria (Fey et al., 2000; Graveland et al., 2010).

As a result, antimicrobial-resistant enterococci, as well as other resistant gut bacteria, can be spread in the environment by fecal residues. These bacteria can rapidly transfer their resistance to other strains through genetic determinants carried by mobile elements. Resistant enterococci are able to persist in the animal intestine, contaminate the environment and food of animal origin, and transfer determinants to human gut's isolates (Tasho and Cho, 2017). Moreover, community people can be exposed to antimicrobial resistant enterococci through direct contact.

Use of antimicrobials can enhance gene transfer between bacteria (Malhotra-Kumar et al., 2007). Gene conjugative transfer is frequent in the human gut, as well as in nature. Enterococci acquire antibiotic resistance genes, e.g., for high-level gentamicin 
resistance and glycopeptides resistance determinants (Willems et al., 2011; Sparo et al., 2012).

Further, enterococci can horizontally transfer resistance genes to relevant bacteria in clinical settings, such as Escherichia coli, Staphylococcus aureus, and Listeria spp. (Verraes et al., 2013).

Generally, severe infections caused by enterococci are treated with a cell-wall active agent-aminoglycoside (mostly gentamicin) combination. The emergence of $\beta$-lactam and glycopeptide resistance and high-level resistance to gentamicin in enterococci has led to the employment of alternative antimicrobials (Arias et al., 2010; Bartash and Nori, 2017).

Figure 1 shows a presumable bidirectional transfer of resistance determinants and/or resistant enterococci between different niches such as human and animal. This transfer can occur through direct contact, foodborne contamination, as well as in health-care settings and the environment (community).

\section{High-Level Vancomycin Resistant Enterococci}

In enterococci, vancomycin resistance is associated with different van genotypes each corresponding with a typical Van phenotype. These genes are chromosomal or extrachromosomal encoded in transposons and/or plasmids. In human E. faecalis and E. faecium, VanA and VanB (inducible resistance) are the most relevant types. vanA gene cluster is most often found on conjugative or non-conjugative plasmids (Cetinkaya et al., 2000; Top et al., 2008). VanA is encoded by Tn1546, or closely related transposons. vanA gene is linked with highlevel resistance to vancomycin and teicoplanin, while variablelevel resistance to vancomycin is associated with a $\operatorname{VanB}$ phenotype. The van $B$ operon is found among large conjugative plasmids or in the chromosome (Cetinkaya et al., 2000). The most frequent vanB subtype, vanB2, is encoded by conjugative transposons Tn1549-/Tn5382-like. It is interesting to note that $\operatorname{Tn} 1549-v a n B$ has also been detected in anaerobes that inhabit the human gut (Dahl et al., 2000; Launay et al., 2006).

VanA is the most prevalent glycopeptide resistance phenotype in Enterococcus linked with human infections, mainly expressed by E. faecium (Freitas et al., 2016). Lester et al. (2006) have proven, in volunteers, the existence of genetic transfer in the human intestine between ingested chicken vanA-E. faecium and non-resistant to vancomycin human E. faecium. It is important to highlight that this research has been performed in a human gut model with its complexity and its diverse microbiota.

Furthermore, there is a global concern regarding plasmidmediated vanA transfer from $E$. faecalis to methicillin-resistant $S$. aureus and their co-colonization, with the likelihood of VanA-S. aureus isolation (Flannagan et al., 2003; Weigel et al., 2003).

In the last decades, vanA-E. faecium were recovered from animals and food of this origin. Initially, the European Union stated that there was a link between Veterinarian use of a glycopeptide (avoparcin) and the emergence of vancomycin resistance (Werner et al., 2008). After avoparcin's ban, glycopeptide-resistance did not disappear. López et al. (2009) reported high-level vancomycin resistant enterococci (4\%) from samples of animal origin 10 years after avoparcin was forbidden. Continuous presence of vancomycin-resistant enterococci in farms and in food of animal origin suggests that is possible the co-transfer of resistance genes located in the same conjugative plasmid, such as vanA and $\operatorname{ermB}$, which encodes for macrolides resistance, widely used in Veterinary medicine. Also, the presence of ABC-type transporter genes and the toxin-antitoxin system may favor the persistence of vancomycin resistance determinants (Aarestrup, 2000). In addition, deficient hygiene conditions in animal husbandry, should not be underestimated (Garcia-Migura et al., 2007). In the same period, a different situation was observed in the United States, since food of animal origin glycopeptide-resistant E. faecium were not detected but, nevertheless, they emerged in health-care settings, turning into a pathogen almost as prevalent as E. faecalis had been so far (Coque et al., 1996; Ramsey and Zilberberg, 2009). However, in Michigan, United States, vanAE.faecium was detected in farm animals where avoparcin was not used; which supports the existence of alternative ways for spreading of van genes, their transfer or carrying isolates from humans to animals (Johnsen et al., 2011; Gordoncillo et al., 2013).

In Argentina, vanA-E. faecium from artisanal food of animal origin was reported by Delpech et al. (2012). Previously, it was observed that animal-origin vancomycin-resistant E. faecium of animal origin were ingested in meats, proving the risk of resistant bacteria colonization when meat products carrying resistant bacteria were consumed (Heuer et al., 2006).

In Argentina, since the late 1990's vancomycin-resistant E. faecium infections have been reported. In several Argentinean hospitals, the prevalence of clonal complex (CC) 17 carrying the vanA gene was detected. Most of these enterococci also expressed high-level aminoglycoside resistance (Corso et al., 2007).

Recently, during a year-period (2013), genetic relatedness (PFGE studies) between vanA enterococci from humans, food and the hospital environment in the District of Tandil (Argentina) was investigated. vanA-E. faecium ( $n$ : 13) were recovered from human, food and hospital environment samples. van A enterococci were distributed among seven clonal types; esp gene was detected in clinical strains. However, the clonal relationship between vanA-E. faecium of clinical and food origin was not found. The clonal relationship was observed among isolates from the hospital environment and from patients (Pourcel et al., 2017).

Bacterial conjugation provides an efficient gene transfer pathway and can be considered as the most relevant mechanism for the increase of antimicrobial resistance (Hammerum, 2012). It is possible that bacteria from food can constitute reservoirs of antimicrobial resistance.

The horizontal gene transfer of vanA-resistance between food strains and human gut microbiota becomes a possible mechanism 


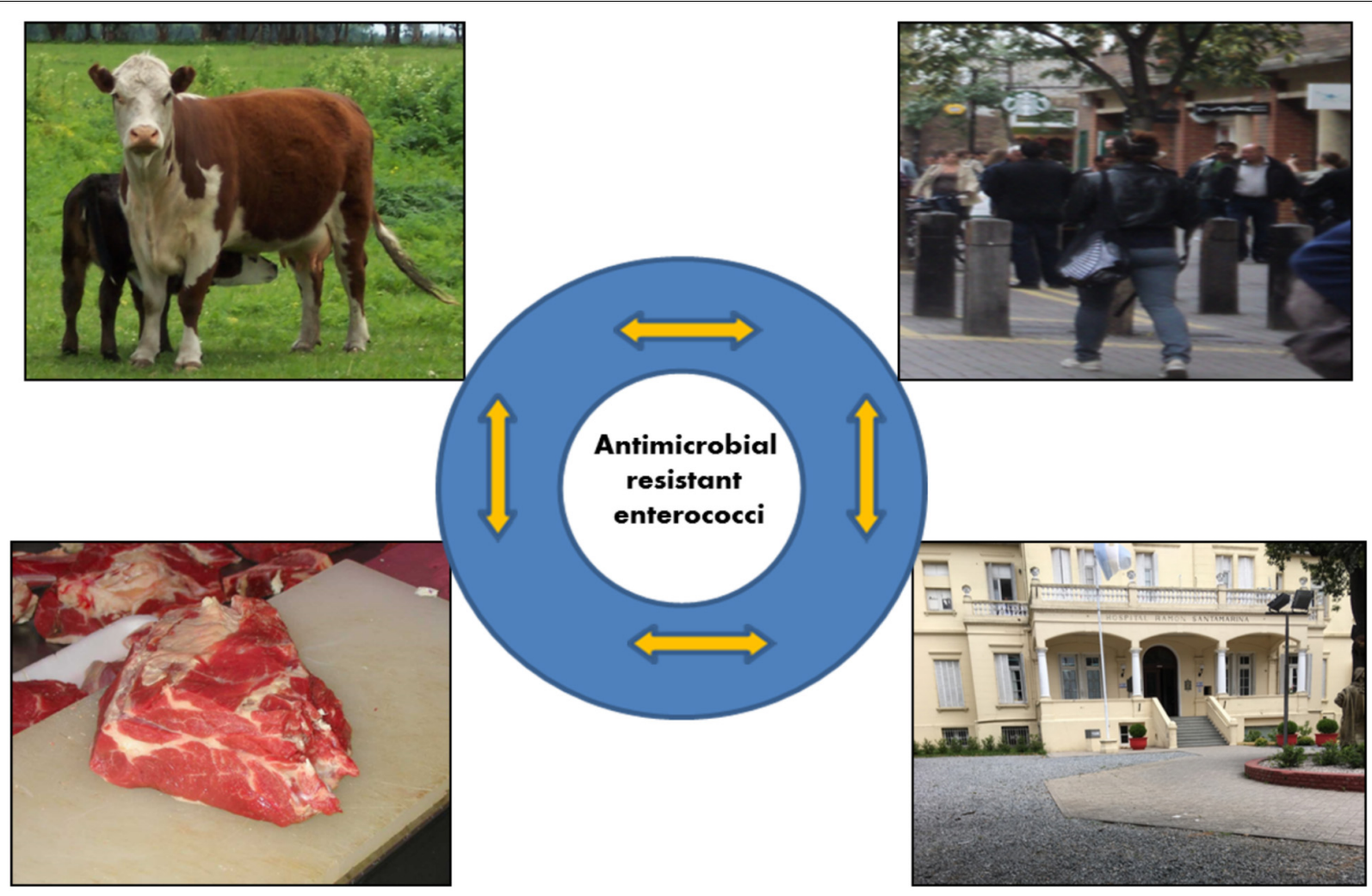

FIGURE 1 | Bidirectional transfer of resistance determinants and/or resistant enterococci between different niches.

of resistance dissemination when enterococci do not fit in the hospital settings (Hammerum et al., 2010).

\section{High-Level Gentamicin Resistant Enterococci}

The most prevalent mechanism of high-level aminoglycoside resistance in clinical bacteria is their enzymatic modification. Three families of aminoglycoside modifying enzymes have been recognized: phosphotransferases (APH), acetyltransferases (AAC), and nucleotidyltransferases (ANT). Genes for aminoglycoside modifying enzymes are often plasmidic, with bacteria-bacteria aminoglycoside resistance dissemination (Bassenden et al., 2016).

The following risk factors for the acquisition of infections with high-level gentamicin resistant enterococci have been identified: previous long-term antimicrobial treatment, number of prescribed antimicrobials, previous surgeries, peri-operative antimicrobial prophylaxis, hospitalization term/antimicrobial treatment, urinary catheterization and renal failure. Infections caused by $E$. faecalis with HLGR constitute a severe risk for patients with invasive conditions and long-term hospitalization (Miranda et al., 2001; Wendelbo et al., 2003; Ceci et al., 2015).

The most ubiquitous HLGR gene among human and food enterococci is aac $\left(6^{\prime}\right)$-Ie-aph ( $\left.2^{\prime \prime}\right)$-Ia that encodes AAC $\left(6^{\prime}\right)$ $\mathrm{APH}\left(2^{\prime \prime}\right)-\mathrm{Ia}$, with acetyltransferase and phosphotransferase activities. Enterococci with this enzyme express resistance to most of the available aminoglycosides (MIC > 2,000 $\mu \mathrm{g} / \mathrm{mL}$ ), except for streptomycin (Leclercq et al., 1992). Generally, $a a c\left(6^{\prime}\right)-I e-a p h\left(2^{\prime \prime}\right)-I a$ gene is flanked by inverted repeats of IS256, composing transposon Tn5281 in E. faecalis as part of a conjugative plasmid (Rosvoll et al., 2012).

Other monofunctional genes encoding aminoglycosidemodifying enzymes have been described, such as class APH $\left(2^{\prime \prime}\right)$-subclass I phosphotransferases, chromosomal [e.g., aph $\left(2^{\prime \prime}\right)$ $I b$ y $\left.a p h\left(2^{\prime \prime}\right)-I d\right]$ and plasmidic [e.g., $\left.a p h\left(2^{\prime \prime}\right)-I c\right]$ genes. These resistance determinants were originally found on Enterococcus species different than E. faecalis and encode enzymes which confer resistance to gentamicin and amikacin. aph $\left(2^{\prime \prime}\right)-I c$ gene is associated with MIC for gentamicin ranging between 128 to $512 \mu \mathrm{g} / \mathrm{mL}$. Nevertheless, aph $\left(2^{\prime \prime}\right)$-Id gene, initially described in human E. casseliflavus, is linked to HLGR. This gene has been detected in clinical vancomycin-resistant E. faecalis (Ramirez and Tolmasky, 2010; Economou et al., 2017).

From 2000 to 2002, in Denmark, the proportion of high-level gentamicin resistant E. faecalis isolates increased from 2 to $6 \%$ in the pig population. Simultaneously, an emergence of HLGR E. faecalis isolates among patients with infective endocarditis was detected in the North Denmark Region (DANMAP, 2002). Afterward, Larsen et al. (2010) demonstrated that all of these isolates (human and pig origin) belonged to the same clonal group, suggesting that pigs were a reservoir for high-level gentamicin resistant $E$. faecalis associated with enterococcal infections. 
Sparo et al. (2012) proved the spread of enterococci with HLGR from animals to humans through the food chain, and also that enterococci isolated from food of animal origin and humans carried the same aminoglycosides resistant genes, as reported, also, by other authors (Hammerum et al., 2007).

Resistance to ampicillin and vancomycin is infrequent, although E. faecalis have been shown to acquire HLGR (Kuch et al., 2012). Recently, over a 1 year period, the presence of cytolysin and HLGR in E. faecalis from human (hospital), animal (chicken feces from a farm) and food (minced meat from shops) origin were studied. Clinical samples were obtained from patients with invasive infections in Hospital Ramón Santamarina from Tandil City, Buenos Aires Province (Argentina). In all enterococci with HLGR, aac (6') -Ie-aph (2')-Ia gene was amplified. aac (6')-Ie-aph (2')-Ia and cylA were detected in human, food and animal E. faecalis, proving its environmental spread (Sparo et al., 2013).

In patients presenting risk factors, a high-level intestinal colonization of $E$. faecalis can become a frequent precursor of human invasive infections by bacterial translocation. This event is favored by the enhanced employment of broad-spectrum antimicrobials that exert significant pressure over the intestinal microbiota, hence, resulting in a likely emergency of multiresistant enterococci. The human gut is a considerable reservoir for microorganisms potentially capable of transfer resistance to conventional antimicrobials. Moreover, the fact that bacteria isolated from food of animal origin can behave as a resistance reservoir needs to be taken into consideration. In vitro studies performed to prove genetic exchange between enterococcal strains from humans and food of animal origin, are not conclusive (Sparo et al., 2012). Therefore, in vivo models for assessing genetic transfer are needed. Research carried out in animal models with their own microbiota it will not be able to reproduce the conditions of the human intestine. The use of human colon microbiota in germ-free mice is proposed as a model for reproducing the interaction between food strains and human gastrointestinal microbiota (Hirayama, 1999). Recently, HLGR determinants transfer from food to human bacteria was proven in an animal model. Immunocompetent BALB$C$ mice, colonized with human feces from an infant with no previous antimicrobial treatment, were used. This study showed evidence of the likelihood of high-level gentamicin resistance horizontal transfer from food to human E. faecalis. Therefore, a gene transfer model in non-sterile mice colonized with human gastrointestinal microbiota was standardized (Sparo et al., 2012).

It is needed to highlight that the rate of HLGR in vancomycinresistant enterococci is higher than in vancomycin-susceptible enterococci strains. Mihajlović Ukropina et al. (2011) studied the frequency of antimicrobial resistance in enterococci isolated from blood cultures. HLGR was detected in vancomycin-resistant strains $(87.6 \%)$ as well as in vancomycin-susceptible strains (9.9\%). Hence, according to this study, HLGR in E. faecium is higher than in E. faecalis.

In an Argentinean study, E. faecalis strains with HLRG (aac (6')-Ie-aph (2')-Ia gene) and without glycopeptide resistance were recovered from human and food samples of animal origin.
PFGE patterns showed four clonal types, and also that there was a clonal relationship between E. faecalis with HLGR isolated from food and those isolated from humans (Pourcel et al., 2017).

\section{Clonal Complexes of High-Level Vancomycin and Gentamicin Resistant Enterococci}

Worldwide, MLST E. faecium data established that the majority of the clinical strains belong to the CC17, most of which are resistant to ciprofloxacin and ampicillin, and contain virulence genes. When new algorithms such as the Bayesian analysis of population structure (BAPS) were applied, it showed that CC17 consists of two large groups with different evolutionary origin: BAPS 2-1, containing sequence-type (ST) 78 and BAPS33 (ST17 and ST18). Most of the drug-resistant clinical isolates of hospital origin belong to both groups. The majority of community-origin isolates were grouped in the BAPS 2-1 group, genetically and evolutionarily different from hospital isolates and those of hospital origin are evolutionarily closer to those of farm animals. A similar trend was detected among vancomycin-resistant E. faecium, investigated in broiler flocks 15 years after the avoparcin ban, diversity was observed as well since they clustered in three BAPS populations (Willems et al., 2012; Bortolaia et al., 2015; Raven et al., 2016).

Several authors have highlighted the predominance of clonal lineages $-17,-18$ and -78 in human clinical isolates of E. faecium. It could be assumed that they have adapted to the intestinal environment and integrate their microbiota (Baquero and Coque, 2011; Faith et al., 2015; Tedim et al., 2015, 2017).

Nowadays, comparison of available genome sequences allowed to support the existence of two clades for E. faecium; one of the animal strains and hospital-associated enterococci (clade A) and another one of community strains (clade B), which includes human commensal isolates. Clade A has been subdivided into $\mathrm{A} 1$, including most of the clinical isolates (lineages ST17, ST18, and ST78) and A2, containing mainly strains of animal origin. It has also been shown that the genome of the strains included in the clade A1 has a larger size than those ones of strains belonging to A2, which seems to support the recent emergence of this clade and the importance of its recombination (Galloway-Peña et al., 2012; Tedim et al., 2015).

Unlike E. faecium, E. faecalis lack a clear structure in clades. Some clones are more frequent in hospitalized patients or in the community. Specifically, CC2 and CC9 both present high-level vancomycin resistance and have been described as highly risky due to their adaptation to the hospital environment and global dissemination (Freitas et al., 2009; Kuch et al., 2012; Guzman Prieto et al., 2016).

E. faecalis CC2, a high-risk CC, is frequently found among health-care associated isolates and represents hospital complexes linked with high-level aminoglycoside resistance (Weng et al., 2013). In addition, E. faecalis CC87, similar to $\mathrm{CC} 2$, expresses multi-drug resistance and can be associated with 
invasive infections (Ruiz-Garbajosa et al., 2006; Tedim et al., 2015).

\section{IMPACT IN HUMAN INFECTIONS AND THERAPEUTIC OPTIONS FOR RESISTANT ENTEROCOCCI}

Among bloodstream infection (BSI) associated with the healthcare environment, Enterococci is the third most common one. Although vancomycin-resistant enterococci have been clinically relevant pathogens for years, the majority of clinical data is retrospective (Wisplinghoff et al., 2004). Nowadays, vancomycin-resistant enterococci are the cause of one-third of all health care associated infections in the United States and one fifth in some European countries (Hidron et al., 2008; European Centre for Disease Prevention and Control [ECDC], 2010). Furthermore, mortality rates in patients with BSIs produced by vancomycin-resistant enterococci range between 20 and 46\% (Han et al., 2009; McKinnell et al., 2011; Twilla et al., 2012).

Treatment of vancomycin-resistant enterococci's BSI is particularly challenging. The therapeutic options include linezolid, daptomycin, quinupristin-dalfopristin, tigecycline, and lipoglycopeptides, such as telavancin, dalbavancin and oritavancin.

Due to limited clinical available data of lipoglycopeptides together with resistance issues in VanA enterococci, the role in systemic vancomycin-resistant enterococci infections for telavancin and dalbavancin is irrelevant. Oritavancin (the lipoglycopeptide with the broadest antibacterial coverage) has shown bactericidal activity against VanA and VanB vancomycinresistant enterococci. This drug was approved for the treatment of acute bacterial skin infections and is currently undergoing clinical trials for the treatment of bacteremia (Zhanel et al., 2010; Messina et al., 2015).

In Europe, Teicoplanin can be used for VanB phenotype infections (Svetitsky et al., 2009).

Tigecycline has not been approved for the treatment of bacteremia because it does not achieve high serum concentrations. This tetracycline can be considered as one of the first-line treatments for polymicrobial intra-abdominal infections associated with vancomycin-resistant enterococci due to its high penetration into the peritoneal space (Arias et al., 2010).

Quinupristin-dalfopristin, effective only against E. faecium, has a high molecular weight, which renders it unable to cross the blood-brain barrier. This, added to the facts that it has frequent side effects and that it easily interacts with other drugs, limits its clinical use (Rubinstein et al., 1999).

Since approval, linezolid has been widely employed for vancomycin-resistant enterococci infections. The clinical success rate can vary based on the infection site and generally range between 50 and $80 \%$. Lower success rates are generally seen in patients with bacteremia and infections without known focus (Birmingham et al., 2003; Kraft et al., 2012; Da Silva et al., 2014; Patel et al., 2016).
Linezolid has shown utility for treating infections by vancomycin-resistant enterococci non-susceptible to daptomycin. Surveillance analysis carried out in 2012 showed 99.5\% susceptibility for linezolid against enterococci in the United States health systems (Mendes et al., 2014). Prolonged use of linezolid has been associated with resistance emergency (Pogue et al., 2007; McGregor et al., 2012).

Tedizolid is a next-generation parenteral and oral oxazolidinone with a broad spectrum bacteriostatic activity against resistant Gram-positive bacteria including VanA and VanB enterococci. It has been approved for the treatment of acute bacterial skin and soft tissues infections, and, currently, clinical trials for bacteremia and pneumonia treatment are being undergone (Rybak et al., 2014).

Daptomycin has been successful for multidrug-resistant enterococci and vancomycin-resistant enterococci infections' treatment. Multiple analyses of the Cubicin Outcomes and Registry Experience (CORE) have shown a higher clinical success rate when used as first-line therapy for vancomycin-resistant enterococci bacteremia, 87-93\% (Sakoulas et al., 2007; Mohr et al., 2009).

$\beta$-lactam antibiotics have been evaluated, in vitro, combined with daptomycin against vancomycin-resistant enterococci, including ampicillin, ceftaroline, ceftobiprole, and ceftriaxone, all of which produced synergistic effects even when $\beta$-lactam resistance was detected (Sakoulas et al., 2012, 2014; Hall Snyder et al., 2014; Werth et al., 2015).

For infectious endocarditis due to ampicillin susceptible and HLGR E. faecalis, ampicillin with ceftriaxone should be considered as an alternative treatment option, since it showed a similar efficacy to the observed ones for ampicillin with gentamicin, in susceptible strains, but with less nephrotoxicity. The saturation of several penicillin-binding proteins is the main reason why this combination presents a desirable bactericidal synergy (Mainardi et al., 1995; Murray, 2000; Fernández-Hidalgo et al., 2013; Economou et al., 2017).

\section{Alternatives/Complementary Therapeutic Options}

Available evidence about infection control and prevention measures (ICP) to reduce vancomycin-resistant enterococci spread in adult hospitalized patients is insufficient. A systematic review published in 2014 (that included 9 studies with 30,949 participants) emphasized the importance of the implementation of hand hygiene program. A decrease of $47 \%$ in the vancomycinresistant enterococci acquisition rate was observed when this measure is applied. Further studies with appropriate methodological design are urgently needed to define if ICP measures have an impact in reducing the acquisition of vancomycin-resistant enterococci among hospitalized patients (De Angelis et al., 2014).

A proposal for controlling antimicrobial resistance dissemination is to reduce antimicrobials employment in animal husbandry and promoting research of novel therapeutic alternatives. Probiotics are "living microorganisms which when administered in adequate amount confer a health benefit on 
the host" (Food and Agriculture Organization/World Health Organzation [FAO/WHO], 2001). These strains improve intestinal microbial balance, provide protection against gut pathogens and modulate the immune system. Probiotics are supplemented into animal feed (cattle, ducks, broilers, and chickens) and have beneficial effects on the food producing animals by enhancing weight gain, increasing egg/milk production, lowering the incidence of disease and mortality rates (Crittenden et al., 2005). Use of probiotics against pathogenic bacteria showed to be effective for reducing food-borne illnesses in consumers, in view of the absence of antibiotics in sub-therapeutic doses (Van Coillie et al., 2007).

A different approach is the use of microbial cell extracts that reduce the risks of bacterial translocation and infection (Sparo et al., 2014; Lemme-Dumit et al., 2018).

Bacteriocins are ribosomally synthesized peptides, with bacteriostatic/bactericidal activity, produced by various bacteria (Gálvez et al., 2007). The use of Gram-positive bacteriocins alone or in combination with antibiotics was proposed as a novel strategy to develop in human and veterinary medicines in order to help conventional antimicrobials against many multi-drug resistant pathogens. These combinations allow decreasing the MIC for achieving a bactericidal effect and, also, reduce undesirable sideeffects of antibiotics (Lebel et al., 2013; Naghmouchi et al., 2013; Delpech et al., 2017). Randomized controlled trials are needed for obtaining scientific evidence about the

\section{REFERENCES}

Aarestrup, F. M. (2000). Characterization of glycopeptide-resistant Enterococcus faecium (GRE) from broilers and pigs in Denmark: genetic evidence that persistence of GRE in pig herds is associated with coselection by resistance to macrolides. J. Clin. Microbiol. 38, 2774-2777.

Andersson, D. I., and Hughes, D. (2014). Microbiological effects of sublethal levels of antibiotics. Nat. Rev. Microbiol. 12, 465-478. doi: 10.1038/nrmicro 3270

Arias, C. A., Contreras, G. A., and Murray, B. E. (2010). Management of multidrugresistant enterococcal infections. Clin. Microbiol. Infect. 16, 555-562. doi: 10. 1111/j.1469-0691.2010.03214.x

Baquero, F., and Coque, T. M. (2011). Multilevel population genetics in antibiotic resistance. FEMS Microbiol. Rev. 35, 705-706. doi: 10.1111/j.1574-6976.2011. 00293.x

Bartash, R., and Nori, P. (2017). Beta-lactam combination therapy for the treatment of Staphylococcus aureus and Enterococcus species bacteremia: a summary and appraisal of the evidence. Int. J. Infect. Dis. 63, 7-12. doi: 10.1016/j.ijid.2017. 07.019

Bassenden, A. V., Rodlonov, D., Shi, K., and Berghuis, A. M. (2016). Structural analysis of the tobramycin and gentamicin clinical resistome reveals limitations for next-generation aminoglycoside design. ACS Chem. Biol. 11, 1339-1346. doi: 10.1021/acschembio.5b01070

Beibei, L., Hong, Z., Xiaoyan, Z., Song, W., Yifei, Z., Zhijia, F., et al. (2015). Probiotic properties of Enterococcus strains isolated from the silage. J. Food Saf. 35, 108-118. doi: 10.1111/jfs. 12165

Birmingham, M. C., Rayner, C. R., Meagher, A. K., Flavin, S. M., Batts, D. H., and Schentag, J. J. (2003). Linezolid for the treatment of multidrug-resistant, grampositive infections: experience from a compassionate-use program. Clin. Infect. Dis. 36, 159-168. doi: 10.1086/345744

Bortolaia, V., Mander, M., Jensen, L. B., Olsen, J. E., and Guardabassi, L. (2015). Persistence of vancomycin resistance in multiple clones of Enterococcus faecium usefulness of these novel compounds against pathogenic enterococci.

\section{CONCLUSION}

Worldwide, enterococcal infections are among the most prevalent within those of nosocomial origin. Antimicrobial multi-resistant enterococci and their drug-resistant determinants spread by direct animal-human contact and/or through animal origin food. As mentioned above, the evidence is based on traditional microbiology and molecular tools, such as PFGE and MLST. Therefore, future studies combining phylogeographic methods with whole genomic sequence will provide reliable information for inferring bacteria movement between host populations.

Nowadays more countries are developing antibiotic-limiting policies, and thus arises a need of searching for an alternative or substitute for these drugs for sustainable food production, such as probiotics and bacteriocins.

\section{AUTHOR CONTRIBUTIONS}

MS and GD contributed to the writing of the microbiological and resistance aspects of the article, revised it and designed the Figure. NG contributed to the clinical and infectological aspects of the work.

isolated from Danish Broilers 15 years after the ban of avoparcin. Antimicrob. Agents Chemother. 59, 2926-2929. doi: 10.1128/AAC.05072-14

Butler, K. M. (2006). Enterococcal infection in children. Semin. Pediatr. Infect. Dis. 17, 128-139. doi: 10.1053/j.spid.2006.06.006

Ceci, M., Delpech, G., Sparo, M., Mezzina, V., Sánchez Bruni, S., and Baldaccini, B. (2015). Clinical and microbiological features of bacteremia caused by Enterococcus faecalis. J. Infect. Dev. Ctries. 9, 1195-1203. doi: 10.3855/jidc. 6587

Cetinkaya, Y., Falk, P., and Mayhall, C. G. (2000). Vancomycin-resistant enterococci. Clin. Microbiol. Rew. 13, 686-707. doi: 10.1128/CMR.13.4.686

Chow, J. W. (2000). Aminoglycoside resistance in enterococci. Clin. Infect. Dis. 31, 586-589. doi: 10.1086/313949

Coque, T. M., Tomayko, J. F., Ricke, S. C., Okhyusen, P. C., and Murray, B. E. (1996). Vancomycin-resistant enterococci from nosocomial, community and animal sources in the United States. Antimicrob. Agents Chemother. 40, 26052609. doi: 10.1128/AAC.40.11.2605

Corso, A. C., Gagetti, P. S., Rodriguez, M. M., Melano, R. G., Ceriana, P. G., Faccone, D. F., et al. (2007). Molecular epidemiology of vancomycin-resistant Enterococcus faecium in Argentina. Int. J. Infect. Dis. 11, 69-75. doi: 10.1016/j. ijid.2006.02.003

Crittenden, R., Bird, A. R., Gopal, P., Henriksson, A., Lee, Y. K., and Playne, M. J. (2005). Probiotic research in Australia, New Zealand and the AsiaPacific region. Curr. Pharm. Des. 11, 37-53. doi: 10.2174/13816120533 82304

Da Silva, N. S., Muniz, V. D., Estofolete, C. F., Furtado, G. H., and Rubio, F. G. (2014). Identification of temporal clusters and risk factors of bacteremia by nosocomial vancomycin-resistant enterococci. Am. J. Infect. Control. 42, 389-392. doi: 10.1016/j.ajic.2013.11.010

Dahl, K. H., Lundblad, E. W., Røkenes, T. P., Olsvik, O., and Sundsfjord, A. (2000). Genetic linkage of the vanB2 gene cluster to Tn5382 in vancomycin-resistant enterococci and characterization of two novel insertion sequences. Microbiology 146, 1469-1479. doi: 10.1099/00221287-146-6-1469 
DANMAP (2002). Use of Antimicrobial Agents and Occurrence of Antimicrobial Resistance in Bacteria from Food Animals, Foods and Humans in Denmark. Available at: https://www.danmap.org/-/media/arkiv/projekt-sites/danmap/ danmap-reports/danmap_2002.pdf?la=en

De Angelis, G., Cataldo, M. A., De Waure, C., Venturiello, S., La Torre, G., Cauda, R., et al. (2014). Infection control and prevention measures to reduce the spread of vancomycin-resistant enterococci in hospitalized patients: a systematic review and meta-analysis. J. Antimicrob. Chemother. 69, 1185-1192. doi: $10.1093 /$ jac/dkt525

Delpech, G., Bistoletti, M., Ceci, M., Lissarrague, S., Sánchez Bruni, S., and Sparo, M. (2017). Bactericidal activity and synergy studies of peptide APCECT7121 against multi-resistant bacteria isolated from human and animal soft-tissue infections. Probiotics Antimicrob. Proteins. 9, 355-362. doi: 10.1007/ s12602-017-9289-3

Delpech, G., Pourcel, G., Schell, C., De Luca, M., Basualdo, J., Bernstein, J., et al. (2012). Antimicrobial resistance profiles of Enterococcus faecalis and Enterococcus faecium isolated from artisanal food of animal origin in Argentina. Foodborne Pathog. Dis. 9, 939-944. doi: 10.1089/fpd.2012.1192

Dewey, C. E., Cox, B. D., Straw, B. E., Bush, E. J., and Hurd, S. (1999). Use of antimicrobials in swine feeds in the United States. Swine Health Prod. 7, 19-25.

Dibner, J. J., and Richards, J. D. (2005). Antibiotic growth promoters in agriculture: history and mode of action. Poult. Sci. 84, 634-643. doi: 10.1093/ps/ 84.4.634

Economou, V., Sakkas, H., Delis, G., and Gousia, P. (2017). “Antibiotic resistance in Enterococcus spp. Friend or foe?," in Foodborne Pathogens and Antibiotic resistance, ed. O. M. Singh (Hoboken, NJ: John Wiley \& Sons).

EFSA (2011). European food safety authority and European Centre for Disease Prevention and Control The European Union summary report on antimicrobial resistance in zoonotic and indicator bacteria from humans, animals and food in the European Union in 2009. EFSA J. 9:2154. doi: 10.2903/j.efsa.2011.2154

European Centre for Disease Prevention and Control [ECDC] (2010). Antimicrobial resistance surveillance in Europe 2009. Annual report of the European Antimicrobial Resistance Surveillance Network (EARS-Net). Stockholm: ECDC.

Faith, J. J., Colombel, J. F., and Gordon, J. I. (2015). Identifying strains that contribute to complex diseases through the study of microbial inheritance. Proc. Natl. Acad. Sci. U.S.A. 112, 633-640. doi: 10.1073/pnas.1418781112

Fernández-Hidalgo, N., Almirante, B., Gavaldá, J., Gurgui, M., Peña, C., de Alarcón, A., et al. (2013). Ampicillin plus ceftriaxone is as effective as ampicillin plus gentamicin for treating Enterococcus faecalis infective endocarditis. Clin. Infect. Dis. 56, 1261-1268. doi: 10.1093/cid/cit052

Fey, P. D., Safranek, T. J., Rupp, M. E., Dunne, E. F., Ribot, E., Iwen, P. C., et al. (2000). Ceftriaxone-resistant salmonella infection acquired by a child from cattle. N. Engl. J. Med. 342, 1242-1249. doi: 10.1056/NEJM200004273421703

Flannagan, S. E., Chow, J. W., Donabedian, S. M., Brown, W. J., Perri, M. B., Zervos, M. J., et al. (2003). Plasmid content of a vancomycin-resistant Enterococcus faecalis isolate from a patient also colonized by Staphylococcus aureus with a VanA phenotype. Antimicrobs. Agents Chemother. 47, 3954-3959. doi: 10.1128/ AAC.47.12.3954-3959.2003

Food and Agriculture Organization/World Health Organzation [FAO/WHO] (2001). Report of a joint FAO/WHO Expert Consultation on Evaluation of health and Nutritional Properties of Probiotics in Food Including Powder Milk with Live Lactic Acid Bacteria. Córdoba: FAO.

Freitas, A. R., Novais, C., Ruiz-Garbajosa, P., Coque, T. M., and Peixe, L. (2009). Clonal expansion within clonal complex 2 and spread of vancomycin resistant plasmids among different genetic lineages of Enterococcus faecalis from Portugal. J. Antimicrob. Chemother. 63, 1104-1111. doi: 10.1093/jac/dkp103

Freitas, A. R., Tedim, A. P., Francia, M. V., Jensen, L. B., Novais, C., Peixe, L., et al. (2016). Multilevel population genetic analysis of vanA and vanB Enterococcus faecium causing nosocomial outbreaks in 27 countries (1986-2012). J. Antimicrob. Chemother. 71, 3351-3366. doi: 10.1093/jac/ dkw312

Galloway-Peña, J., Roh, J. H., Latorre, M., Qin, X., and Murray, B. E. (2012). Genomic and SNP analyses demonstrate a distant separation of the hospital and community-associated clades of Enterococcus faecium. PLoS One 7:e30187. doi: 10.1371/journal.pone.0030187
Gálvez, A., Abriouel, H., López, R. L., and Ben Omar, N. (2007). Bacteriocinbased strategies for food biopreservation. Int. J. Food Microbiol. 120, 51-70. doi: 10.1016/j.ijfoodmicro.2007.06.001

Garcia-Migura, L., Liebana, E., Jensen, L. B., Barnes, S., and Pleydell, E. (2007). A longitudinal study to assess the persistence of vancomycinresistant Enterococcus faecium (VREF) on an intensive broiler farm in the United Kingdom. FEMS Microbiol. Lett. 275, 319-325. doi: 10.1111/j.15746968.2007.00911.x

Ghosh, A., and Zurek, L. (2015). in Antimicrobial Resistance and Food Safety. Methods and Techniques, eds C.-Y. Chen, X. Yan, and C. R. Jackson (Amsterdam: Elsevier Inc), doi: 10.1016/C2013-0-15443-8

Gordoncillo, M. J., Donabedian, S., Bartlett, P. C., Perri, M., Zervos, M., Kirkwood, R., et al. (2013). Isolation and molecular characterization of vancomycin-resistant Enterococcus faecium from swine in Michigan, USA. Zoonoses Public Health 60, 319-326. doi: 10.1111/zph.12008

Graveland, H., Wagenaar, J. A., Heesterbeek, H., Mevius, D., van Duijkeren, E., and Heederik, D. (2010). Methicillin resistant Staphylococcus aureus ST398 in veal calf farming: human MRSA carriage related with animal antimicrobial usage and farm hygiene. PLoS One 5:e10990. doi: 10.1371/journal.pone.0010990

Guzman Prieto, A. M., van Schaik, W., Rogers, M. R., Coque, T. M., Baquero, F., Corander, J., et al. (2016). Global emergence and dissemination of enterococci as nosocomial pathogens: attack of the clones? Front. Microbiol. 7:788. doi: 10.3389/fmicb.2016.00788

Hall Snyder, A., Werth, B. J., Barber, K. E., Sakoulas, G., and Rybak, M. (2014). Evaluation of the novel combination of daptomycin plus ceftriaxone against vancomycin-resistant enterococci in an in vitro pharmacokinetic/pharmacodynamic simulated endocardial vegetation model. J. Antimicrob. Chemother. 69, 2148-2154. doi: 10.1093/jac/dku113

Hammerum, A. M. (2012). Enterococci of animal origin and their significance for public health. Clin. Microbiol. Infect. 18, 619-625. doi: 10.1111/j.1469-0691. 2012.03829.x

Hammerum, A. M., Heuer, O. E., Emborg, H.-E., Bagger-Skjøt, L., Jensen, V. F., Rogues, A.-M., et al. (2007). Danish integrated antimicrobial resistance monitoring and research program. Emerg. Infect. Dis. 13, 1633-1639. doi: 10. 3201/eid1311.070421

Hammerum, A. M., Lester, C. H., and Heuer, O. E. (2010). Antimicrobial-resistant enterococci in animals and meat: a human health hazard? Foodborne Pathog. Dis. 7, 1137-1146. doi: 10.1089/fpd.2010.0552

Han, S. H., Chin, B. S., Lee, H. S., Jeong, S. J., Choi, H. K., Kim, C. O., et al. (2009). Vancomycin-resistant enterococci bacteremia: risk factors for mortality and influence of antimicrobial therapy on clinical outcome. J. Infect. 58, 182-190. doi: 10.1016/j.jinf.2009.01.013

Heuer, O. E., Hammerum, A. M., Collignon, P., and Wegener, H. C. (2006). Human health hazard from antimicrobial-resistant enterococci in animals and food. Clin. Infect. Dis. 43, 911-916. doi: 10.1086/507534

Hidron, A. I., Edwards, J. R., Patel, J., Horan, T. C., Sievert, D. M., Pollock, D. A., et al. (2008). NHSN annual update: antimicrobial-resistant pathogens associated with health care-associated infections: annual summary of data reported to the National Health care Safety Network at the Centre for Disease Control and Prevention, 2006-2007. Infect. Control Hosp. Epidemiol. 29, 9961011. doi: $10.1086 / 591861$

Hirayama, K. (1999). Ex-germ free mice harboring intestinal microbiota derived from other animal species as an experimental model for ecology and metabolism of intestinal bacteria. Exp. Anim. 48, 219-227. doi: 10.1538/ expanim.48.219

Johnsen, P. J., Townsend, J. P., Bøhn, T., Simonsen, G. S., Sundsfjord, A., and Nielsen, K. M. (2011). Retrospective evidence for a biological cost of vancomycin resistance determinants in the absence of glycopeptide selective pressures. J. Antimicrob. Chemother. 66, 608-610. doi: 10.1093/jac/dkq512

Kraft, S., Mackler, E., Schlickman, P., Welch, K., and DePestel, D. D. (2012). Outcomes of therapy: vancomycin-resistant enterococcal bacteremia in hematology and bone marrow transplant patients. Support Care Cancer 20, 1935-1936. doi: 10.1007/s00520-012-1440-9

Kuch, A., Willems, R. J., Werner, G., Coque, T. M., Hammerum, A. M., Sundsfjord, A., et al. (2012). Insight into antimicrobial susceptibility and population structure of contemporary human Enterococcus faecalis isolates from Europe. J. Antimicrob. Chemother. 67, 551-558. doi: 10.1093/jac/dkr544 
Kuehn, B. M. (2014). FDA moves to curb antibiotic use in livestock. JAMA 311, 347-348. doi: 10.1001/jama.2013.285704

Larsen, J., Schonheider, H. C., Lester, C. H., Olsen, S. S., Porsbo, L. J., GarciaMigura, L., et al. (2010). Porcine-origin gentamicin-resistant Enterococcus faecalis in humans. Denmark. Emerg. Infect. Dis. 16, 682-684. doi: 10.3201/ eid1604.090500

Launay, A., Ballard, S. A., Johnson, P. D., Grayson, M. L., and Lambert, T. (2006). Transfer of vancomycin resistance transposon Tn 1549 from Clostridium symbiosum to Enterococcus spp. in the gut of gnotobiotic mice. Antimicrob. Agents Chemother. 50, 1054-1062. doi: 10.1128/AAC.50.3.1054-1062.2006

Lebel, G., Piché, F., Frenette, M., Gottschalk, M., and Grenier, D. (2013). Antimicrobial activity of nisin against the swine pathogen Streptococcus suis and its synergistic interaction with antibiotics. Peptides 50, 19-23. doi: 10.1016/ j.peptides.2013.09.014

Leclercq, R., Dutka-Malen, S., Brisson-Noël, A., Molinas, C., Derlot, E., Arthur, M., et al. (1992). Resistance of enterococci to aminoglycosides and glycopeptides. Clin. Infect. Dis. 15, 495-501. doi: 10.1093/clind/15.3.495

Lemme-Dumit, J. M., Polti, M. A., Perdigon, G., and Galdeano, C. M. (2018). Probiotic bacteria cell walls stimulate the activity of the intestinal epithelial cells and macrophage functionality. Benef. Microbes. 9, 153-164. doi: 10.3920/ BM2016.0220

Lester, C. H., Frimodt-Møller, N., Sørensen, T. L., Monnet, D. L., and Hammerum, A. M. (2006). In vivo transfer of the vanA resistance gene from an Enterococcus faecium isolate of animal origin to an E. faecium isolate of human origin in the intestines of human volunteers. Antimicrob. Agents Chemother. 50, 596-599. doi: 10.1128/AAC.50.2.596-599.2006

López, M., Sáenz, Y., Rojo-Bezares, B., Martínez, S., del Campo, R., Ruiz-Larrea, F., et al. (2009). Detection of vanA and vanB2-containing enterococci from food samples in Spain, including Enterococcus faecium strains of CC17 and the new singleton ST425. Int. J. Food Microbiol. 133, 172-178. doi: 10.1016/j. ijfoodmicro.2009.05.020

Love, D. C., Davis, M. F., Bassett, A., Gunther, A., and Nachman, K. E. (2011). Dose imprecision and resistance: free-choice medicated feeds in industrial food animal production in the United States. Environ. Health Perspect. 119, 279-283. doi: 10.1289/ehp.1002625

Mainardi, J. L., Gutmann, L., Acar, J. F., and Goldstein, F. W. (1995). Synergistic effect of amoxicillin and cefotaxime against Enterococcus faecalis. Antimicrob. Agents Chemother. 39, 1984-1987. doi: 10.1128/AAC.39.9.1984

Malhotra-Kumar, S., Lammens, C., Coenen, S., Van Herck, K., and Goossens, H. (2007). Effect of azithromycin and clarithromycin therapy on pharyngeal carriage of macrolide-resistant streptococci in healthy volunteers: a randomised, double-blind, placebo-controlled study. Lancet 369, 482-490. doi: 10.1016/S0140-6736(07)60235-9

Marshall, B. M., and Levy, S. B. (2011). Food animals and antimicrobials: impacts on human health. Clin. Microbiol. Rev. 24, 718-733. doi: 10.1128/CMR.0000211

McDonald, L. C., Rossiter, S., Mackinson, C., Wang, Y. Y., Johnson, S., Sullivan, M., et al. (2001). Quinupristin-dalfopristin-resistant Enterococcus faecium on chicken and in human stool specimens. N. Engl. J. Med. 345, 1155-1160. doi: 10.1056/NEJMoa010805

McGregor, J. C., Hartung, D. M., Allen, G. P., Taplitz, R. A., Traver, R., Tong, T., et al. (2012). Risk factors associated with linezolid-non susceptible enterococcal infections. Am. J. Infect. Control. 40, 886-887. doi: 10.1016/j.ajic.2011.11.005

McKinnell, J. A., Patel, M., Shirley, R. M., Kunz, D. F., Moser, S. A., and Baddley, J. W. (2011). Observational study of the epidemiology and outcomes of vancomycin-resistant Enterococcus bacteraemia treated with newer antimicrobial agents. Epidemiol. Infect. 139, 1342-1350. doi: 10.1017/ S0950268810002475

Mendes, R. E., Flamm, R. K., Hogan, P. A., Ross, J. E., and Jones, R. N. (2014). Summary of linezolid activity and resistance mechanisms detected during the 2012 LEADER surveillance program for the United States. Antimicrob. Agents Chemother. 58, 1243-1247. doi: 10.1128/AAC.02112-13

Messina, J. A., Fowler, V. G. Jr., and Corey, G. R. (2015). Oritavancin for acute bacterial skin and skin structure infection. Expert. Opin. Pharmacother. 16, 1091-1098. doi: 10.1517/14656566.2015.1026256

Mihajlović Ukropina, M., Jelesić, Z., Gusman, V., and Milosavljević, B. (2011). Frecquency of vancomycin-resistant enterococci isolated from blood cultures from 2008 to 2010. Med. Pregl. 64, 481-485. doi: 10.2298/MPNS1110481M
Miranda, G., Lee, L., Kelly, C., Solórzano, F., Leaños, B., Muñoz, O., et al. (2001). Antimicrobial resistance from enterococci in a pediatric hospital. Plasmids in Enterococcus faecalis isolates with high-level gentamicin and streptomycin resistance. Arch. Med. Res. 32, 159-163. doi: 10.1016/S0188-4409(01) 00265-X

Mohr, J. F., Friedrich, L. V., Yankelev, S., and Lamp, K. C. (2009). Daptomycin for the treatment of enterococcal bacteraemia: results from the Cubicin Outcomes Registry and Experience (CORE). Int. J. Antimicrob. Agents 33, 543-548. doi: 10.1016/j.ijantimicag.2008.12.007

Murray, B. E. (2000). Vancomycin-resistant enterococcal infections. N. Engl. J. Med. 342, 710-721. doi: 10.1056/NEJM200003093421007

Naghmouchi, K., Baah, J., Hober, D., Jouy, E., Rubrecht, C., Sané, F., et al. (2013). Synergistic effect between colistin and bacteriocins in controlling Gram-negative pathogens and their potential to reduce antibiotic toxicity in mammalian epithelial cells. Antimicrob. Agents Chemother. 57, 2719-2725. doi: 10.1128/AAC.02328-12

Nieto-Arribas, P., Seseña, S., Poveda, J. M., Chicón, R., Cabezas, L., and Palop, L. (2011). Enterococcus populations in artisanal Manchego cheese: biodiversity, technological and safety aspects. Food Microbiol. 28, 891-899. doi: 10.1016/j. fm.2010.12.005

Normanno, G., Corrente, M., La Salandra, G., Dambrosio, A., Quaglia, N. C., Parisi, A., et al. (2007). Methicillin-resistant Staphylococcus aureus (MRSA) in foods of animal origin product in Italy. Int. J. Food Microbiol. 117, 219-222. doi: 10.1016/j.ijfoodmicro.2007.04.006

Patel, K., Kabir, R., Ahmad, S., and Allen, S. L. (2016). Assessing outcomes of adult oncology patients treated with linezolid versus daptomycin for bacteremia due to vancomycin-resistant Enterococcus. J. Oncol. Pharm. Pract. 22, 212-218. doi: $10.1177 / 1078155214556523$

Pogue, J. M., Paterson, D. L., Pasculle, A. W., and Potoski, B. A. (2007). Determination of risk factors associated with isolation of linezolid resistant strains of vancomycin-resistant Enterococcus. Infect. Control Hosp. Epidemiol. 28, 1382-1388. doi: $10.1086 / 523276$

Pourcel, G., Sparo, M., Corso, A., Delpech, G., Gagetti, P., de Luca, M. M., et al. (2017). Molecular genetic profiling of clinical and foodborne strains of enterococci with high level resistance to gentamicin and vancomycin. Clin. Microbiol. Open Access. 6, 272. doi: 10.4172/2327-5073. 1000272

Ramirez, M. S., and Tolmasky, M. E. (2010). Aminoglycoside modifying enzymes. Drug Resist. Updat. 13, 151-171. doi: 10.1016/j.drup. 2010.08.00

Ramsey, A. M., and Zilberberg, M. D. (2009). Secular trends of hospitalization with vancomycin-resistant Enterococcus infection in the United States, 2000-2006. Infect. Control Hosp. Epidemiol. 30, 184-186. doi: 10.1086/ 593956

Raven, K. E., Reuter, S., Reynolds, R., Brodrick, H. J., Russell, J. E., Török, M. E., et al. (2016). A decade of genomic history for healthcare-associated Enterococcus faecium in the United Kingdom and Ireland. Genome Res. 26, 1388-1396. doi: 10.1101/gr.204024.116

Reyes, K., Zervos, M., and John, J. (2017). "Enterococcal infections in adults," in Antimicrobial Drug Resistance. Clinical and Epidemiological Aspects, eds D. L. Mayers, J. D. Sobel, M. Ouellette, K. S. Kaye, and D. Marchaim (Berlin: Springer International Publishing).

Ribeiro, T., Oliveira, M., Fraqueza, M. J., Luaková, A., Elias, M., Tenreriro, R., et al. (2011). Antibiotic resistance and virulence factors among enterococci isolated from Chouriço, a traditional Portuguese dry fermented sausage. J. Food Protect. 74, 465-469. doi: 10.4315/0362-028X.JFP-10-309

Rosvoll, T. C., Lindstad, B. L., Lunde, T. M., Hegstad, K., Aasnaes, B., Hammerum, A. M., et al. (2012). Increased high-level gentamicin resistance in invasive Enterococcus faecium is associated with aac $\left(6^{\prime}\right) \mathrm{Ie}$-aph $\left(2^{\prime \prime}\right) \mathrm{Ia}$ encoding transferable megaplasmids hosted by major hospital-adapted lineages. FEMS Immunol. Med. Microbiol. 66, 166-176. doi: 10.1111/j.1574-695X.2012. 00997.x

Rubinstein, E., Prokocimer, P., and Talbot, G. H. (1999). Safety and tolerability of quinupristin/ dalfopristin: administration guidelines. J. Antimicrob. Chemother 44(Suppl. A), 37-46. doi: 10.1093/jac/44.suppl_1.37

Ruiz-Garbajosa, P., Bonten, M. J. M., Robinson, D. A., Top, J., Nallapareddy, S. R., Torres, C., et al. (2006). Multilocus sequence typing scheme for Enterococcus faecalis reveals hospital-adapted genetic complexes in a background of high 
rates of recombination. J. Clin. Microbiol. 44, 2220-2228. doi: 10.1128/JCM. 02596-05

Ruzauskas, M., Virgailis, M., Šiugždinienė, R., Sužiedèlienė, E., Šeputienè, V., Daugelavičius, R., et al. (2009). Antimicrobial resistance of Enterococcus spp. isolated from livestock in Lithuania. Vet. Arhiv. 79, 439-449.

Rybak, J. M., Marx, K., and Martin, C. A. (2014). Early experience with tedizolid: clinical efficacy, pharmacodynamics, and resistance. Pharmacotherapy 34, 1198-1208. doi: 10.1002/phar.1491

Sakoulas, G., Bayer, A. S., Pogliano, J., Tsuji, B. T., Yang, S. J., Mishra, N. N., et al. (2012). Ampicillin enhances daptomycin- and cationic host defense peptide-mediated killing of ampicillin- and vancomycin-resistant Enterococcus faecium. Antimicrob. Agents Chemother. 56, 838-844. doi: 10.1128/AAC.055 51-11

Sakoulas, G., Golan, Y., Lamp, K. C., Friedrich, L. V., and Russo, R. (2007). Daptomycin in the treatment of bacteremia. Am. J. Med. 120, S21-S27. doi: 10.1016/j.amjmed.2007.07.012

Sakoulas, G., Rose, W., Nonejuie, P., Olson, J., Pogliano, J., Humphries, R., et al. (2014). Ceftaroline restores daptomycin activity against daptomycinnonsusceptible vancomycin-resistant Enterococcus faecium. Antimicrob. Agents Chemother. 58, 1494-1500. doi: 10.1128/AAC.02274-13

Sánchez Valenzuela, A., Lavilla Lerma, L., Benomar, N., Gálvez, A., Pérez Pulido, R., and Abriouel, H. (2013). Phenotypic and molecular antibiotic resistance profile of Enterococcus faecalis and Enterococcus faecium isolated from different traditional fermented foods. Foodborne Pathog. Dis. 10, 143-149. doi: 10.1089/ fpd.2012.1279

Sparo, M., Delpech, G., Batisttelli, S., and Basualdo, J. A. (2014). Immunomodulatory properties of cell wall extract from Enterococcus faecalis CECT7121. Braz. J. Infect. Dis. 18, 551-555. doi: 10.1016/j.bjid.2014.05.005

Sparo, M., Delpech, G., Pourcel, G., Schell, C., De Luca, M. M., Bernstein, J., et al. (2013). Citolisina y alto nivel de resistencia a gentamicina en Enterococcus faecalis de distinto origen (in Spanish). Rev. Argent. Zoonosis Enferm. Infecc. Emerg. 8, 5-10.

Sparo, M., Urbizu, L., Solana, M. V., Pourcel, G., Delpech, G., Confalonieri, A., et al. (2012). High-level resistance to gentamicin: genetic transfer between Enterococcus faecalis isolated from food of animal origin and human microbiota. Lett. Appl. Microbiol. 54, 119-125. doi: 10.1111/j.1472-765X.2011. 03182.x

Svetitsky, S., Leibovici, L., and Paul, M. (2009). Comparative efficacy and safety of vancomycin versus teicoplanin: systematic review and meta-analysis. Antimicrob. Agents Chemother. 53, 4069-4079. doi: 10.1128/AAC.00341-09

Tasho, R. P., and Cho, J. Y. (2017). "Entry routes of veterinary antibiotics in the environment," in Antibiotics and Antibiotics Resistance Genes in Soils Monitoring, Toxicity, Risk Assessment and Management, eds M. Z. Hashmi, V. Strezov, and A. Varma (Berlin: Springer International Publishing).

Tedim, A. P., Ruiz-Garbajosa, P., Corander, J., Rodríguez, C. M., Cantón, R., Willems, R. J., et al. (2015). Population biology of intestinal enterococcus isolates from hospitalized and nonhospitalized individuals in different age groups. Appl Environ. Microbiol. 81, 1820-1831. doi: 10.1128/AEM.03661-14

Tedim, A. P., Ruiz-Garbajosa, P., Rodriguez, M. C., Rodriguez-Baños, M., Lanza, V. F., Verdoy, L., et al. (2017). Long-term clonal dynamics of Enterococcus faecium strains causing bloodstream infections (1995-2015) in Spain. J. Antimicrob. Chemoter. 72, 48-55. doi: 10.1093/jac/dkw366

Top, J., Willems, R., and Bonten, M. (2008). Emergence of CC17 Enterococcus faecium: from commensal to hospital-adapted pathogen. FEMS Immunol. Med. Microbiol. 52, 297-308. doi: 10.1111/j.1574-695X.2008.00383.x

Twilla, J. D., Finch, C. K., Usery, J. B., Gelfand, M. S., Hudson, J. Q., and Broyles, J. E. (2012). Vancomycin-resistant Enterococcus bacteremia: an evaluation of treatment with linezolid or daptomycin. J. Hosp. Med. 7, 243-248. doi: 10.1002/ jhm.994

Ubeda, C., Taur, Y., Jenq, R. R., Equinda, M. J., Son, T., Samstein, M., et al. (2010). Vancomycin-resistant Enterococcus domination of intestinal microbiota is enabled by antibiotic treatment in mice and precedes bloodstream invasion in humans. J. Clin. Invest. 120, 4332-4341. doi: 10.1172/JCI43918
Van Coillie, E., Goris, J., Cleenwerck, I., Grijspeerdt, K., Botteldoorn, N., Van Immerseel, F., et al. (2007). Identification of lactobacilli isolated from the cloaca and vagina of laying hens and characterization for potential use as probiotics to control Salmonella enteritidis. J. Appl. Microbiol. 102, 1095-1106.

Van Immerseel, F., Fievez, V., De Buck, J., Pasmans, F., Martel, A., Haesebrouck, F., et al. (2004). Microencapsulated short-chain fatty acids in feed modify colonization and invasion early after infection with Salmonella enteritidis in young chickens. Poult. Sci. 83, 69-74. doi: 10.1093/ps/83.1.69

Verraes, C., Van Boxstael, S., Van Meervenne, E., Van Coillie, E., Butaye, P., Catry, B., et al. (2013). Antimicrobial resistance in the food chain: A review. Int. J. Environ. Res. Public Health. 10, 2643-2669. doi: 10.3390/ijerph10072643

Weigel, L. M., Clewell, D. B., Gill, S. R., Clark, N. C., McDougal, L. K., Flannagan, S. E., et al. (2003). Genetic analysis of a high-level vancomycin-resistant isolate of Staphylococcus aureus. Science 302, 1569-1571. doi: 10.1126/science.1090956

Wendelbo, O., Jureen, R., Eidec, G. E., Digranes, A., Langeland, N., and Harthug, S. (2003). Outbreak of infection with high-level gentamicin-resistant Enterococcus faecalis (HLGRE) in a Norwegian hospital. Clin. Microbiol. Infect. 9, 662-669. doi: 10.1046/j.1469-0691.2003.00668.x

Weng, P. L., Ramli, R., Nor Shamudsin, M., Cheah, Y.-Q., and Hamat, R. A. (2013). High genetic diversity of Enterococcus faecium and Enterococcus faecalis clinical isolates by Pulsed-Field Gel Electrophoresis and Multilocus Sequence Typing from a hospital in Malaysia. BioMed. Res. Int. 2013:938937. doi: 10.1155/2013/ 938937

Werner, G., Coque, T. M., Franz, C. M., Grohmann, E., Hegstad, K., Jensen, L., et al. (2013). Antibiotic resistant enterococci-tales of a drug resistance gene trafficker. Int. J. Med. Microbiol. 303, 360-379. doi: 10.1016/j.ijmm.2013.03.001

Werner, G., Coque, T. M., Hammerum, A. M., Hope, R., Hryniewicz, W., Johnson, A., et al. (2008). Emergence and spread of vancomycin resistance among enterococci in Europe. Euro. Surveill. 13:19046.

Werth, B. J., Barber, K. E., Tran, K. N., Nonejuie, P., Sakoulas, G., Pogliano, J., et al. (2015). Ceftobiprole and ampicillin increase daptomycin susceptibility of daptomycin-susceptible and -resistant VRE. J. Antimicrob. Chemother. 70, 489-493. doi: 10.1093/jac/dku386

Willems, R. J., Hanage, W. P., Bessen, D. E., and Fell, E. J. (2011). Population biology of Gram-positive pathogens: high-risk clones for dissemination of antibiotic resistance. FEMS Microbiol. Rev. 35, 872-900. doi: 10.1111/j.15746976.2011.00284.x

Willems, R. J., Top, J., van Schaik, W., Leavis, H., Bonten, M., Sirén, J., et al. (2012). Restricted gene flow among hospital subpopulations of Enterococcus faecium. mBio 3:e00151-12. doi: 10.1128/mBio.00151-12

Wisplinghoff, H., Bischoff, T., Tallent, S. M., Seifert, H., Wenzel, R. P., and Edmond, M. B. (2004). Nosocomial blood stream infections in US hospitals: analysis of 24,179 cases from a prospective nationwide surveillance study. Clin. Infect. Dis. 39, 309-317. doi: 10.1086/421946

Woodford, N., and Livermore, D. M. (2009). Infections caused by Gram-positive bacteria: a review of the global challenge. J. Infect. 59(Suppl. 1), S4-S16. doi: 10.1016/S0163-4453(09)60003-7

Zhanel, G. G., Calic, D., Schweizer, F., Zelenitsky, S., Adam, H., LagacéWiens, P. R., et al. (2010). New lipoglycopeptides: a comparative review of dalbavancin, oritavancin and telavancin. Drugs 70, 859-886. doi: 10.2165/ 11534440-000000000-00000

Conflict of Interest Statement: The authors declare that the research was conducted in the absence of any commercial or financial relationships that could be construed as a potential conflict of interest.

Copyright (C) 2018 Sparo, Delpech and García Allende. This is an open-access article distributed under the terms of the Creative Commons Attribution License (CC BY). The use, distribution or reproduction in other forums is permitted, provided the original author(s) and the copyright owner(s) are credited and that the original publication in this journal is cited, in accordance with accepted academic practice. No use, distribution or reproduction is permitted which does not comply with these terms. 